\title{
Glutamine affects T24 bladder cancer cell proliferation by activating STAT3 through ROS and glutaminolysis
}

\author{
NINGCHUAN SUN ${ }^{1,2^{*}}$, YE LIANG $^{2 *}$, YUANBIN CHEN $^{2}$, LIPING WANG $^{2}$, DAN LI $^{2}$, \\ ZHIJUAN LIANG ${ }^{2}$, LIJIANG SUN ${ }^{*}$, YONGHUA WANG ${ }^{1}$ and HAITAO NIU ${ }^{1,2}$ \\ ${ }^{1}$ Department of Urology, Affiliated Hospital of Qingdao University; \\ ${ }^{2}$ Key Laboratory of Urinary System Diseases, Qingdao, Shandong 266003, P.R. China
}

Received June 3, 2019; Accepted September 24, 2019

DOI: $10.3892 /$ ijmm.2019.4385

\begin{abstract}
Changes in metabolism are common phenomena in tumors. Glutamine (Gln) has been documented to play a critical role in tumor growth. In this study, we aimed to to explore the mechanisms through which bladder cancer cells utilize Gln to fulfill their biosynthetic needs during proliferation. In addition, the roles of Gln in the tricarboxylic acid (TCA) cycle, reactive oxygen species (ROS) regulation, and signal transducer and activator of transcription 3 (STAT3) expression were examined in vitro in the T24 bladder cancer cell line. The results revealed that the T24 cell line was markedly Gln-dependent and that Gln supplementation promoted $\mathrm{T} 24$ proliferation through the actions of Gln as a ROS moderator and as a metabolic fuel in the TCA cycle. Importantly, extracellular Gln deprivation deregulated the production of the transcription factor, STAT3. Additionally, STAT3 expression was affected by the degree of Gln metabolism, as regulated by Gln intermediates and ROS. Thus, on the whole, the findings of this study demonstrate that Gln promotes the proliferation of the Gln-dependent bladder cancer cell line, T24, by supplementing adenosine triphosphate (ATP) production and neutralizing ROS to activate the STAT3 pathway.
\end{abstract}

\section{Introduction}

Bladder cancer, the ninth most common type of cancer worldwide, is associated with a high recurrence rate (1). Considering that the tumor microenvironment (TME) plays an important role in bladder cancer growth, research on the

Correspondence to: Dr Yonghua Wang or Dr Haitao Niu, Department of Urology, Affiliated Hospital of Qingdao University, 16 Jiangsu Road, Shinan, Qingdao, Shandong 266003, P.R. China

E-mail: doctorwangyonghua@163.com

E-mail: niuht0532@126.com

*Contributed equally

Key words: glutamine, proliferation, urinary bladder neoplasms, signal transducer and activator of transcription 3, reactive oxygen species, adenosine triphosphate, therapy
TME has been prevalent. The richly diverse TME implies that tumor cells need adequate nutrients for growth through energy metabolism. Glutamine (Gln), one of the most abundant amino acids in the TME, is mainly involved in critical physiological processes, such as energy synthesis, biosynthesis, antioxidant defense and cell signaling regulation $(2,3)$.

In fact, Gln can serve as an alternative metabolite to drive the tricarboxylic acid (TCA) cycle for energy generation, exerting a 'replenishment effect' (4). After being transferred into a cell via a transporter on the cell membrane, Gln participates in the TCA cycle with glutamate (Glu) via glutaminase (GLS), which produces 2-oxoglutarate $(\alpha \mathrm{KG})$ via Glu dehydrogenase (GLUD1) (5).

In addition to being metabolic fuel, Gln can help neutralize reactive oxygen species (ROS) $(6,7)$. ROS, such as superoxide anions and hydrogen peroxide, can act as intracellular second messengers and activate apoptosis (8). Glu, the product of glutaminolysis, is also directly used for the synthesis of the antioxidant, glutathione (9). A significant fraction of Gln-derived carbon can be used to produce NADPH for redox balance (10). Thus, Gln becomes an essential amino acid for Gln-dependent cancer cells, and this process is related to cancer cell viability $(2,11,12)$.

However, in contrast to the above description, Cacace et al (13) proposed that Gln activates signal transducer and activator of transcription 3 (STAT3) to control cancer cell proliferation, independently of its activity as a metabolic fuel or ROS scavenger. The overactivation of STAT3, a protein present in the cytoplasm that is coupled with the tyrosine phosphorylation signaling pathway, results in aberrant cell proliferation and apoptosis, and promotes tumor formation and development $(14,15)$. It is well known that STAT3 is activated through phosphorylation on Y705 or S727, after which it binds to extracellular signaling proteins. The activated proteins can be translocated to the nucleus, where they bind to the promoters of genes involved in cell survival, cell cycling, invasion, migration and angiogenesis (16).

Therefore, we sought to determine whether the characteristics of Gln metabolism in the bladder cancer cell line, T24, are consistent with the mechanisms proposed by Cacace et al (13). Existing research on the mechanisms through which Gln promotes the proliferation of bladder cancer cells remains inadequate. 


\section{Materials and methods}

Cells and reagents. The bladder cancer cell line, T24, purchased from the Cell Bank of the Chinese Academy of Sciences, was routinely cultured in RPMI-1640 medium (BI) containing $2 \mathrm{~g} / 1$ glucose and $300 \mathrm{mg} / \mathrm{l} \mathrm{Gln}$. The assay medium was modified Eagle's medium (BI) without glucose or Gln reconstituted with $2 \mathrm{~g} / \mathrm{l}$ of glucose. Both media were supplemented with $10 \%$ fetal bovine serum and $1 \%$ penicillin and streptomycin. The cells were grown at $37^{\circ} \mathrm{C}$ in a humidified $5 \% \mathrm{CO}_{2}$ atmosphere. L-Gln (Sigma-Aldrich), D-(+)-glucose (Sigma-Aldrich), 0-100 $\mu \mathrm{M}$ 6-diazo-5-oxo-L-norleucine (Don) (Sigma-Aldrich), 0-10 mM N-acetylcysteine (NAC) (MCE), $2 \mathrm{mM}$ L-glutamic acid dimethyl ester hydrochloride (Glu) (Sigma-Aldrich) and $2 \mathrm{mM}$ dimethyl $\alpha \mathrm{KG}$ (Sigma-Aldrich) were used during the experiment. The reagents were dissolved either in ultrapure water or directly in modified Eagle's medium (BI) according to the manufacturer's indications. All drugs and reagents were administered to adherent cells in fresh assay medium.

Cell proliferation assay. Cell proliferation was assessed by 3-(4,5-dimethylthiazol-2-yl)-2,5-diphenyltetrazolium bromide (MTT) assay. Briefly, the T24 cells were plated into 96-well plates at a density of $5 \times 10^{3}$ cells/well. Following $24 \mathrm{~h}$ of incubation at $37^{\circ} \mathrm{C}$, the medium was replaced with $200 \mu \mathrm{l}$ of specific medium for 24,48 or $72 \mathrm{~h}$. A total of $10 \mu \mathrm{l}$ of MTT was added to the wells, and the cells were incubated for a further $4 \mathrm{~h}$ at $37^{\circ} \mathrm{C}$. Finally, $100 \mu \mathrm{l}$ of dimethyl sulfoxide (DMSO) were added to each well, and the wells were gently mixed for $1 \mathrm{~min}$. Finally, the cell numbers were measured spectrophotometrically by an absorbance microplate reader (Thermo Fisher Scientific) at $490 \mathrm{~nm}$.

Cell cycle assays. The T24 cells were seeded in 6-well plates, grown for $24 \mathrm{~h}$, and then incubated in $\mathrm{G} \ln (+)$ or $\mathrm{Gln}(-)$ medium. After 24 or $48 \mathrm{~h}$, a cell cycle assay was conducted as previously described (17). Following the instructions of the kit, the cells were fixed with $75 \%$ cold ethanol overnight and then washed with phosphate-buffered saline (PBS). Subsequently, propidium iodide $(50 \mu \mathrm{g} / \mathrm{ml})$ containing RNase was added to the cells for DNA staining before flow cytometric analysis.

Measurement of intracellular adenosine triphosphate (ATP) levels. The T24 cells were cultured in a 6-well plate at a density of $2 \times 10^{5}$ cells/well for $24 \mathrm{~h}$ and then cultured under various Gln conditions for $48 \mathrm{~h}$. The supernatant was added to a 96-well plate with a black border according to the protocol provided by the manufacturer for a commercial ATP assay kit (Beyotime Institute of Biotechnology) and as previously described by Castaneda et al (18). The assay buffer was gently mixed with the substrate at room temperature, and the mixed reagent $(100 \mu \mathrm{l})$ was added to each well. The plate was then incubated with shaking for $15 \mathrm{~min}$ at room temperature. Following incubation, luminescence was measured using a microplate reader (Beckman Coulter).

Measurement of intracellular ROS levels. ROS levels were determined using 2',7'-dichlorodihydrofluorescein diacetate $\left(\mathrm{H}_{2} \mathrm{DCF}-\mathrm{DA}\right)$ with a Reactive Oxygen Species Assay kit (Beyotime Institute of Biotechnology). The T24 cells were pre-seeded into 6-well plates at $2 \times 10^{5} /$ well and then cultured with $G \ln (+)$ or Gln(-) medium for $48 \mathrm{~h}$. The cells were then treated with $10 \mathrm{mM} \mathrm{H}_{2}$ DCF-DA dissolved in PBS $(1 \mathrm{ml})$ at $37^{\circ} \mathrm{C}$ for $20 \mathrm{~min}$. The assay was conducted as previously described (19). The fluorescence intensity was monitored at an excitation wavelength of $488 \mathrm{~nm}$ and an emission wavelength of $530 \mathrm{~nm}$. In addition, Applied 1.0-2.0 $\mathrm{ml}$ of $5 \mu \mathrm{M}_{\text {MitoSOX }}^{\mathrm{TM}}$ reagent working solution was added to cover the cells adhering to the coverslip. The cells were incubated for $10 \mathrm{~min}$ at $37^{\circ} \mathrm{C}$, protected from light. The cells were then washed gently 3 times with warm buffer as described in the MitoSOX ${ }^{\mathrm{TM}}$ Red mitochondrial superoxide indicator *for live-cell imaging* (Molecular Probes). Finally, we observed the intracellular red fluorescence under a confocal fluorescence microscope (BD Biosciences). ROSUP was added to the positive control well as a positive control, which can significantly increase the level of ROS following stimulation of the cells for 20-30 min.

Apoptosis assay. The T24 cells were pre-seeded in a 6-well plate at a density of $3 \times 10^{5}$ cells/well with RPMI- 1640 medium for $24 \mathrm{~h}$ and were then cultured with $\mathrm{Gln}(+), \mathrm{G} \ln (-), \mathrm{Gln}(-)+\alpha \mathrm{KG}$, or Gln(-)+Glu medium for $48 \mathrm{~h}$. Cell morphology was assessed as previously described (20) with an Apoptosis and Necrosis Assay kit (Beyotime Institute of Biotechnology). Briefly, cells in all groups were washed 3 times with cold PBS, and the cells in the supernatant and those that adhered to the plate were then collected. Following incubation with Annexin V-FITC for $15 \mathrm{~min}$ in the dark at $37^{\circ} \mathrm{C}$, the cells were washed 3 more times with cold PBS. The results were analyzed by flow cytometry (BD Biosciences).

Western blot analysis. The cells were lysed in cell lysis buffer (Beyotime Institute of Biotechnology) containing $1 \mathrm{mM}$ phenylmethylsulfonyl fluoride. Following determination with the BCA method, the protein samples ( $30 \mu \mathrm{g}$ protein/lane) were then subjected to SDS-PAGE and transferred to a nitrocellulose membrane. The membrane was blocked with $5 \%$ bovine serum albumin and subsequently incubated overnight at $4^{\circ} \mathrm{C}$ with the appropriate primary antibodies. The membrane was then incubated with horseradish peroxidase-conjugated goat anti-rabbit (111-035-045)/mouse (111-035-062) IgG (1:10,000, Jackson ImmunoResearch Laboratories, Inc.) at $4^{\circ} \mathrm{C}$ for $2 \mathrm{~h}$. To verify equal loading of the samples, the same membrane was incubated with a monoclonal $\beta$-actin antibody followed by horseradish peroxidase-conjugated goat anti-rabbit IgG. The protein bands were visualized with a FluorChem Q instrument (ProteinSimple, type: AlphaImager). The data were analyzed using ImageJ software (NIH). Primary antibodies against total-STAT3 (9139T), p-Y705-STAT3 (4113S), c-Myc (13987S), Bcl2 (15071S) and $\beta$-actin (3700S) were purchased from Cell Signaling Technology, while primary antibodies against proliferating cell nuclear antigen (PCNA, ab18197), Gls (ab156876) and Glud1 (ab168352), were purchased from Abcam.

Statistical analysis. Each experiment was performed at least 3 times. All values are presented as the means \pm SD in Prism 7 statistical software. Differences between 3 or more groups were determined by one-way analysis of variance (ANOVA) followed by a post hoc test with Sidak's multiple comparisons test in Prism 7. In addition, t-tests was performed for 
A

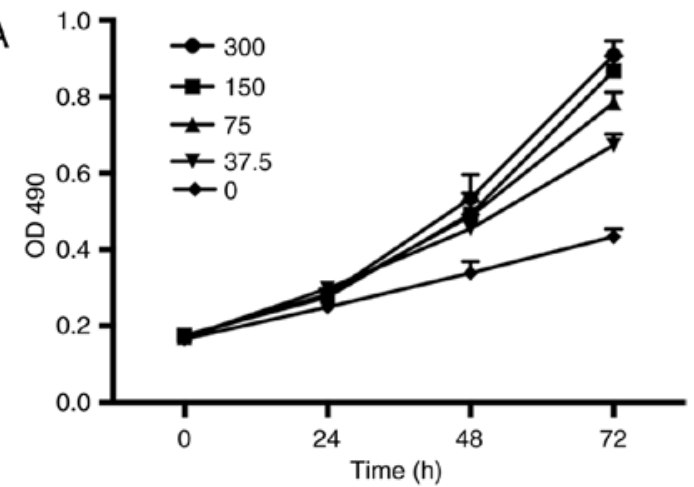

C FL2-W, FL2-A subset/cell cycle
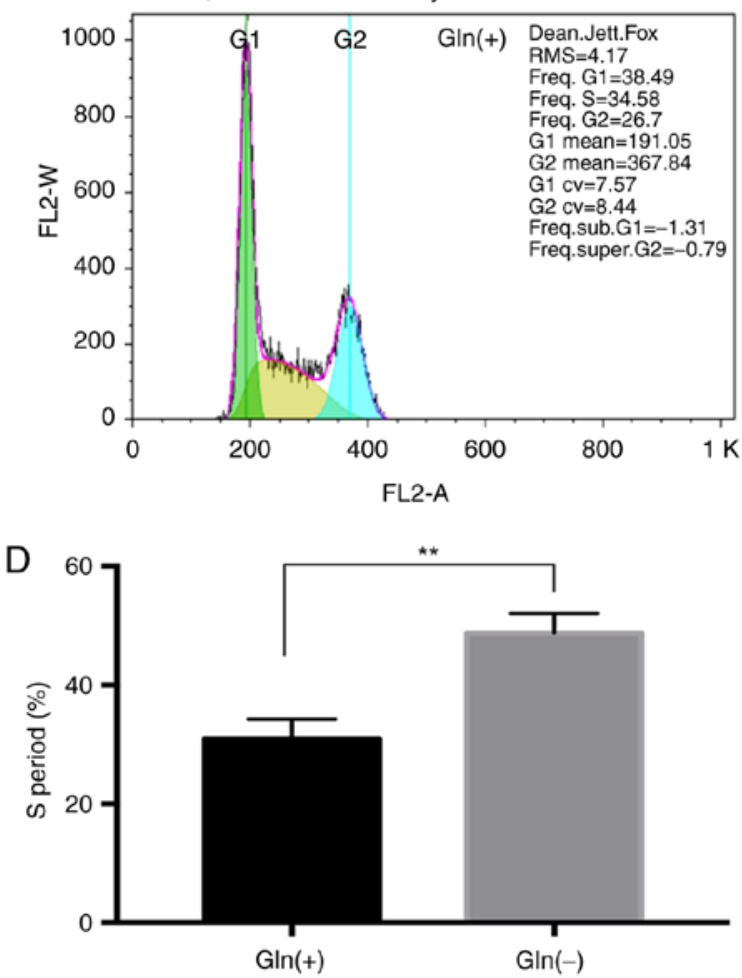
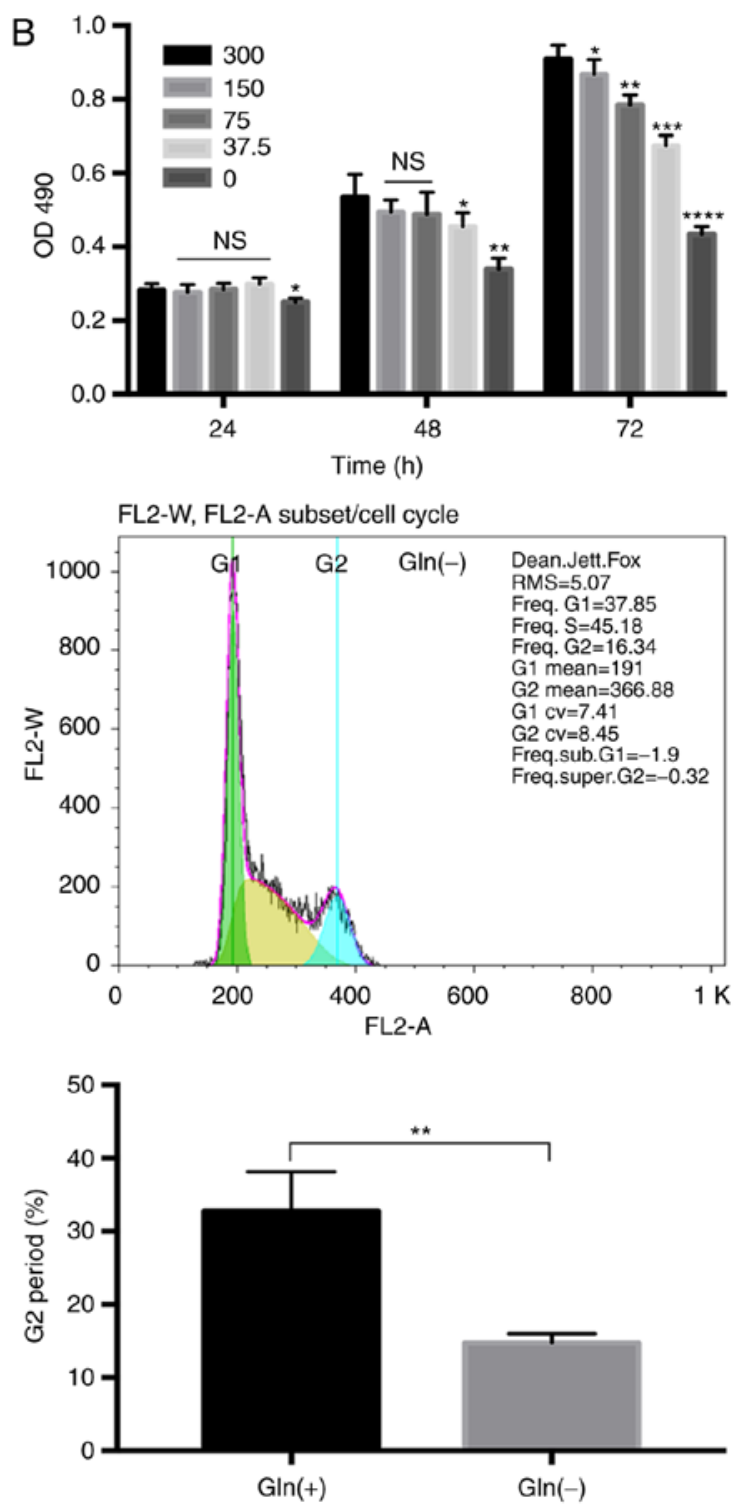

Figure 1. Gln affects T24 bladder cancer cell proliferation. (A) The proliferation rate was positively affected by exposure to increasing Gln concentrations from $0 \mathrm{mg} / 1$ [Gln(-)] to $300 \mathrm{mg} / \mathrm{l}[\mathrm{Gln}(+)]$ for 24,48 and $72 \mathrm{~h}(\mathrm{n}=6)$. (B) Analysis of the effects of varying Gln concentration gradients on cell proliferation at 24,48 and $72 \mathrm{~h}$. Two-way ANOVA with a test for homogeneity of variance was used to compare the cell lines. (C) Analysis of the proportions of T24 tumor cells in different phases of the cell cycle under Gln (+) or Gln(-) conditions for $48 \mathrm{~h}$ by flow cytometric analysis. (D) Statistical analysis of the results in (C) the results were obtained from 3 independent repeated experiments. t-tests were used to compare the Gln $(+)$ and Gln $(-)$ groups. ${ }^{*} \mathrm{P}<0.05,{ }^{* *} \mathrm{P}<0.01,{ }^{* * *} \mathrm{P}<0.001,{ }^{* * * *} \mathrm{P}<0.0001$; ns, no significance. In all tests, $300 \mathrm{mg} / 1$ was used $\mathrm{Gln}(+)$ as the control condition. Gln, glutamine.

comparisons between 2 groups. Differences were considered statistically significant at $\mathrm{P}<0.05$.

\section{Results}

Effects of Gln on T24 bladder cancer cell proliferation. The results of MTT assay revealed that the proliferation rate of the T24 cells was indeed positively associated with the Gln concentration. No apparent differences were observed in the bladder cancer cell proliferation rate among the groups cultured with the different Gln concentrations $(0,37.5,75,150$ and $300 \mathrm{mg} / \mathrm{l}$ ) after $24 \mathrm{~h}$. However, the proliferation rates of the T24 cells decreased with the decreasing Gln concentrations at 48 and $72 \mathrm{~h}(\mathrm{P}<0.05)$. The proliferation rate of the Gln deprivation group was lower than that of the other Gln concentration groups (Fig. 1A). As the differences in the proliferation rate were most evident at $72 \mathrm{~h}$ (Fig. 1B), we selected $72 \mathrm{~h}$ as the time point for use in further experiments.

Furthermore, compared with that in the Gln(+) group $(300 \mathrm{mg} / \mathrm{l})$, the proportion of cells in the $\mathrm{S}$ phase of the cell cycle in the Gln(-) group (0 mg/l) was approximately $11 \%$ higher on average, while the proportion of cells in the $\mathrm{G} 2$ phase was almost $11 \%$ lower; cell cycle analysis thus revealed that Gln deprivation caused T24 growth arrest in the S phase (Fig. 1C and D).

Effect of the inhibition of Gln uptake on the proliferation of T24 bladder cancer cells. To further identify the critical role of Gln in T24 cell proliferation, we used a Gln analog, Don, to inhibit T24 Gln utilization, as Don competes for Gln uptake. The effects of various Don concentrations $(0,12.5$, 25, 50 and $100 \mu \mathrm{M})$ on $\mathrm{T} 24$ proliferation were evaluated. The 

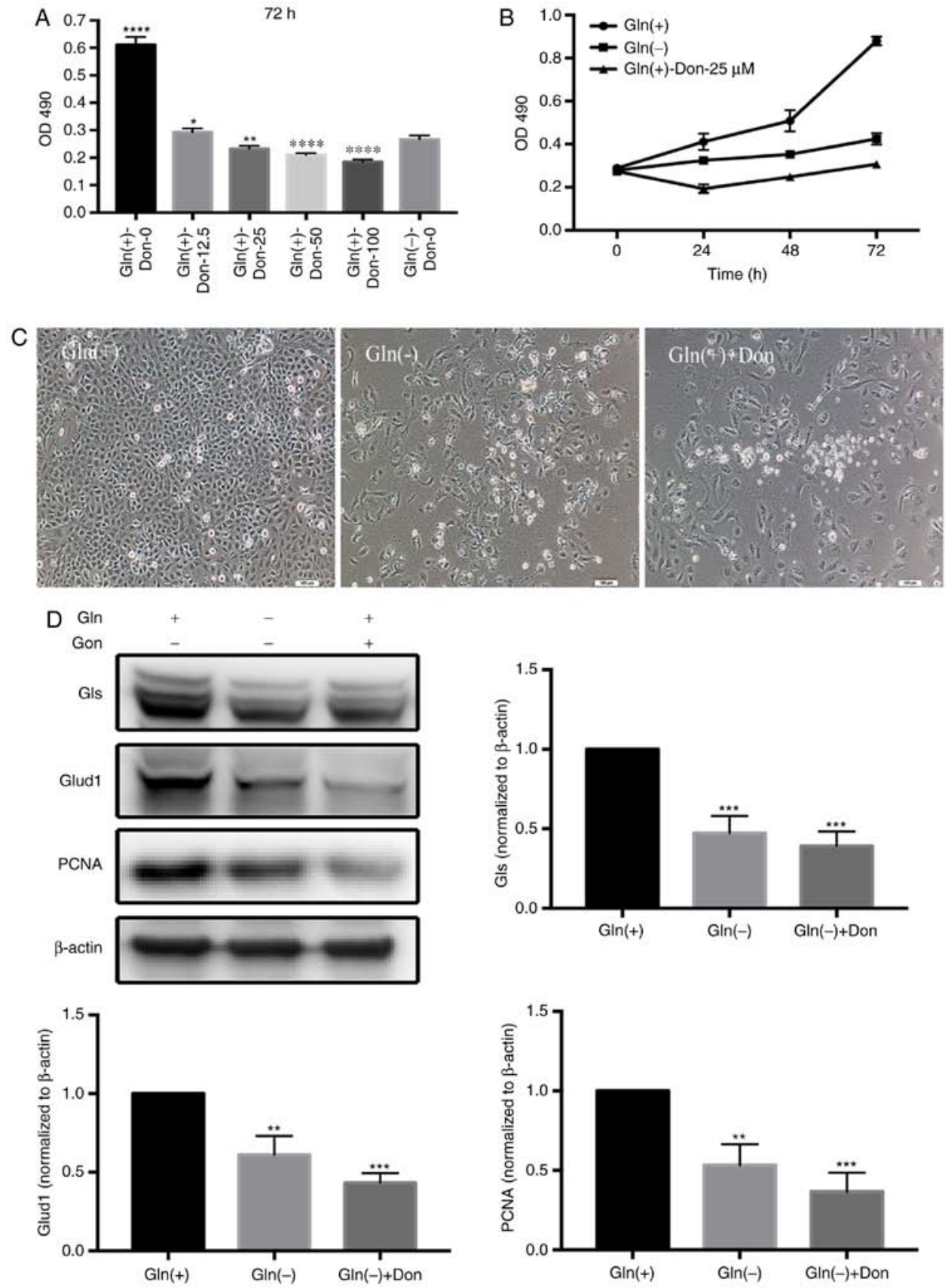

Figure 2. Gln analogs affect T24 bladder cancer cell proliferation similarly to Gln starvation. (A) Analysis of the effects of a range of Don concentrations on T24 proliferation rates. (B) Gln deprivation affected the proliferation rates of T24 bladder cancer cells incubated with the optimum Don concentration $(25 \mu \mathrm{M})$ for 24,48 and $72 \mathrm{~h}$. (C) The growth status of T24 bladder cancer under Gln(+), Gln(-), and Gln(+)+Don conditions. Scale bars, $100 \mu \mathrm{m}$. (D) Western blot analysis of proteins associated with Gln metabolism (Gls and Glud1) and proliferation (PCNA) using Gln(+) as the control. One-way ANOVA with a test for homogeneity of variance was used to compare the cell lines. ${ }^{*} \mathrm{P}<0.05,{ }^{* * *} \mathrm{P}<0.01,{ }^{* * *} \mathrm{P}<0.001,{ }^{* * * * *} \mathrm{P}<0.0001$. Gln, glutamine; Don, 6-diazo-5-oxo-L-norleucine; Gls, glutaminase; Glud1, Glu dehydrogenase.

results revealed that the proliferation rates of the T24 cells gradually decreased with the increasing concentrations of Don. Additionally, Don most effectively inhibited T24 cell proliferation in the presence of extracellular Gln at the $25 \mu \mathrm{M}$ concentration (Fig. 2A), contributing to our selection of $25 \mu \mathrm{M}$ as the optimal concentration of Don at $72 \mathrm{~h}$ (Fig. 2B). In fact, compared with the $\mathrm{Gln}(+)$ group, the different $\mathrm{Gln}(+)$-Don groups exhibited significantly decreased proliferation rates similar to those in the Gln(-) group (Fig. 2C). In addition, the levels of proteins associated with both Gln metabolism (GLS and GLUD1) and proliferation (PCNA) were significantly decreased in the $\mathrm{Gln}(-)$ group and the $\mathrm{G} \ln (+)+$ Don groups compared with the Gln(+) group (Fig. 2D).

Glutaminolysis-dependent ATP production in T24 cells. As shown in Fig. 3A, Gln serves as a crucial carbon source for cellular bioenergetic and biosynthetic needs. Cell proliferation is associated with a high influx of Gln-derived carbon into the TCA cycle (4). In this study, we found that the ATP levels in the T24 bladder cancer cells decreased gradually with the reduction in Gln (Fig. 3B). We divided the cells into 4 groups and treated two of these with the cell-permeable precursors, 
A
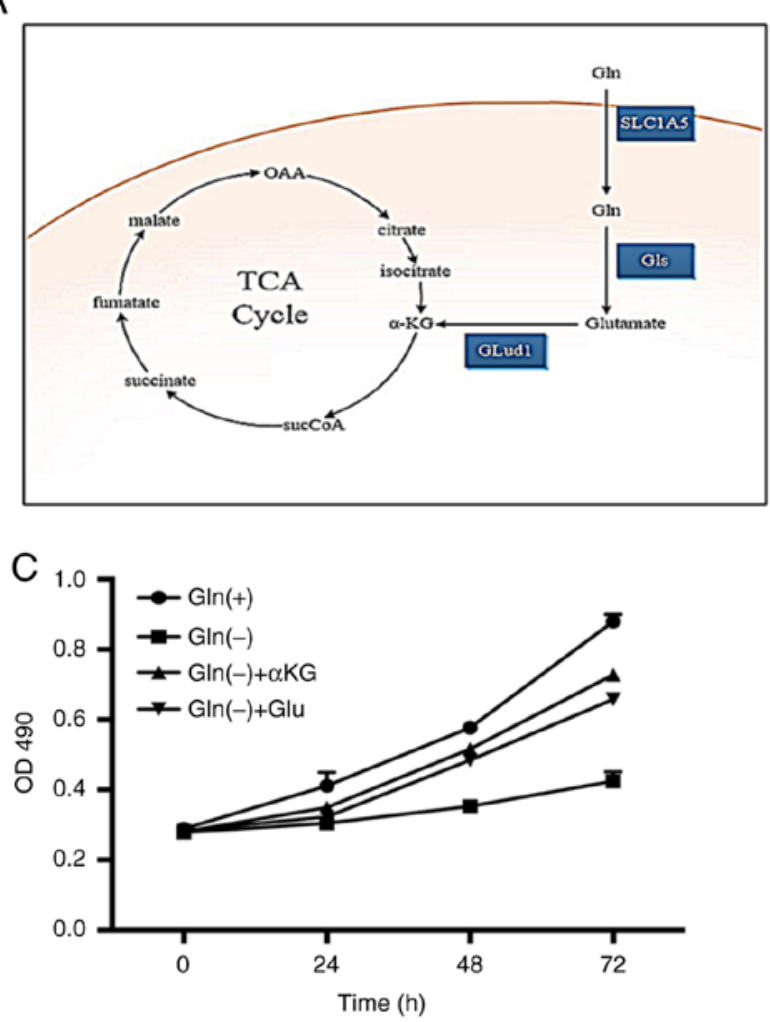
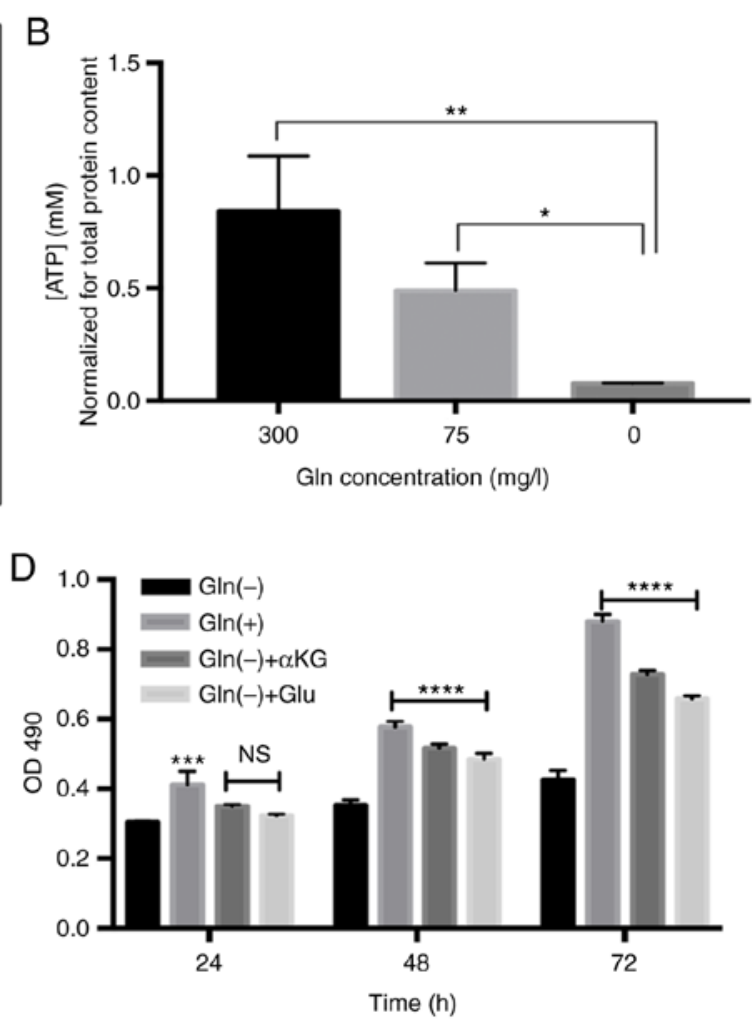

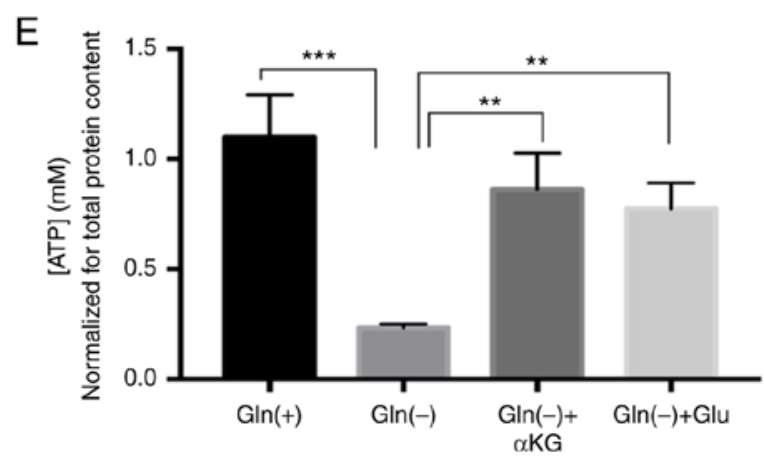

Figure 3. Gln glutaminolysis dependently promotes ATP production. (A) Gln contributes to the TCA cycle metabolite pool. Enzymes involved in the metabolism of Gln, Gls and Glud1. (B) Gln modified ATP content in T24 cells. (C and D) Supplementation with Gln catabolism intermediates partially restored cellular proliferation at 24, 48 and $72 \mathrm{~h}$; $\mathrm{Gln}(-)$ was used as the control condition. (E) Supplementation with Gln catabolism intermediates significantly restored cellular ATP levels. One-way ANOVA with a test for homogeneity of variance was used to compare the cell lines. ${ }^{*} \mathrm{P}<0.05,{ }^{* * *} \mathrm{P}<0.01,{ }^{* * * *} \mathrm{P}<0.001,{ }^{* * * * *} \mathrm{P}<0.0001$; ns, no significance. Gln, glutamine; Gls, glutaminase; Glud1, Glu dehydrogenase; SLC1A5, recombinant solute carrier family 1, member 5.

dimethyl-Glu and dimethyl $\alpha \mathrm{KG}$, creating the $\mathrm{Gln}(+), \mathrm{Gln}(-)$, $\mathrm{G} \ln (-)+\alpha \mathrm{KG}$, and $\mathrm{Gln}(-)+\mathrm{Glu}$ groups. When used at a $2 \mathrm{mM}$ concentration (13), both Glu and $\alpha \mathrm{KG}$ were capable of restoring the proliferation of the Gln-deprived T24 cells (Fig. 3C). No obvious differences were observed among the groups after $24 \mathrm{~h}$; however, the restoring effects of Glu and $\alpha \mathrm{KG}$ on cell proliferation were evident at 48 and $72 \mathrm{~h}$ (Fig. 3D). In addition, both Glu and $\alpha \mathrm{KG}$ were able to restore ATP production in the Gln-deprived cells (Fig. 3E). In summary, these data indicate that Gln can promote T24 cell proliferation through ATP supplementation via glutaminolysis.

Effect of Gln on ROS production in T24 cells. The levels of ROS in the Gln(-) group were markedly higher than those in the Gln(+) group (Fig. 4A and B). NAC, a classic ROS inhibitor, was used to create $\mathrm{Gln}(-)+\mathrm{NAC}$ groups in addition to the
$\mathrm{Gln}(+)$ and $\mathrm{Gln}(-)$ groups. NAC restored the proliferation rate of the Gln-deprived T24 cells. As the concentration of NAC increased, the proliferation rate of the T24 cells also gradually increased in the Gln(-)+NAC groups compared with the $\mathrm{Gln}(-)$ group. At the $10 \mathrm{mM}$ optimal concentration, the proliferation rate of the $G \ln (-)+N A C$ group was equivalent to that of the $\mathrm{Gln}(+)$ group (Fig. 4C). We compared the viability of the cells in the $\mathrm{G} \ln (+), \mathrm{Gln}(-)$, and $\mathrm{Gln}(-)+\mathrm{NAC}$ groups at 24,48 and $72 \mathrm{~h}$ by MTT assays. The results revealed that the proliferation rate was lower in the Gln(-) group than in the other 2 groups, and at 24 and $48 \mathrm{~h}$, the proliferation rate was much greater in the Gln(-)+NAC group than that in the other groups. However, at $72 \mathrm{~h}$, there was no obvious difference between the $\mathrm{Gln}(+)$ group and the Gln(-)+NAC group (Fig. 4D). In addition, the analysis of the fluorescence intensities in the different treatment groups by intracellular ROS fluorescence staining confirmed that Gln 

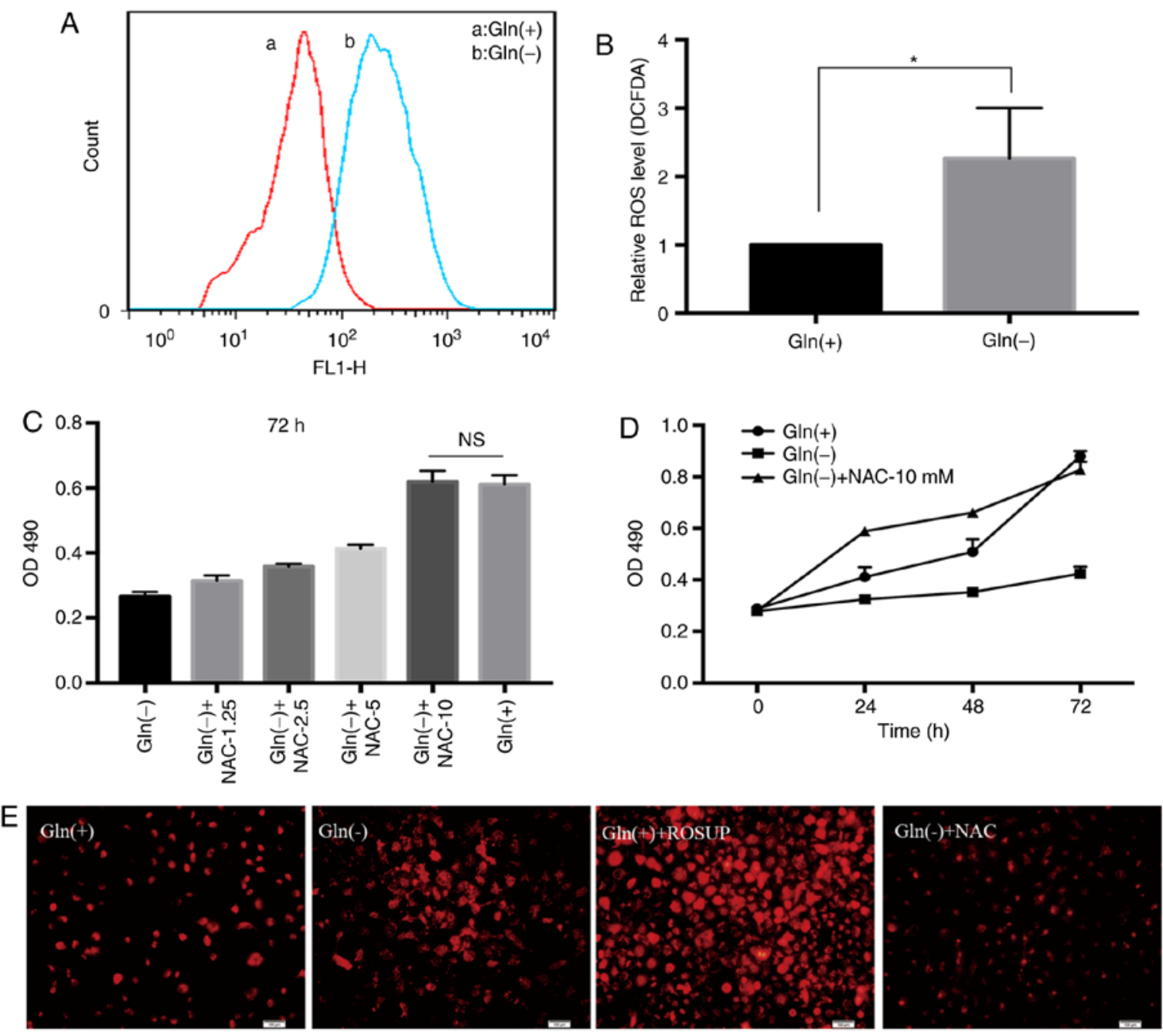

Figure 4. Gln promotes T24 cell proliferation by influencing ROS production. (A) Gln deprivation increased ROS concentrations in T24 cells (B) Independent-sample t-tests were used to compare the $\mathrm{Gln}(+)$ and $\mathrm{Gln}(-)$ groups. (C) Analysis of the proliferation of T24 cells cultured for $72 \mathrm{~h}$ with a range of concentrations of NAC; Gln(-) was used as the control condition. (D) Effects of ROS on the proliferation rates of T24 bladder cancer cells treated with the optimum NAC concentration of $10 \mathrm{mM}$ for 24,48 and $72 \mathrm{~h}$. (E) The fluorescence intensity in the different treatment groups (the Gln(+), Gln(-), Gln(+)+ROSUP, and $\mathrm{Gln}(-)+\mathrm{NAC}$ groups), was analyzed by intracellular ROS fluorescence staining. ns indicates no significance; "P<0.05. Scale bars, $100 \mu \mathrm{m}$. Gln, glutamine; NAC, N-acetylcysteine.

deprivation increased ROS concentrations in the T24 bladder cancer cells (Fig. 4E).

Gln promotes cell viability via its effects on glutaminolysis and ROS production. The analysis of the apoptotic effects of different conditions, including $\mathrm{G} \ln (+), \mathrm{G} \ln (-), \mathrm{G} \ln (-)+\alpha \mathrm{KG}, \mathrm{Gln}(-)+\mathrm{Glu}$, and $\mathrm{G} \ln (-)+\mathrm{NAC}$, revealed that the $\mathrm{Gln}(-)$ group exhibited the highest apoptotic rate among the 5 groups. The groups exposed to the glutaminolysis intermediates, $\alpha \mathrm{KG}$ and Glu, exhibited lower apoptotic rates than those in the Gln(-) group. In addition, the ROS scavenger, NAC, restored cell viability in the absence of Gln (Fig. 5). Thus, increasing glutaminolysis intermediate levels and reducing intracellular ROS levels decreased the apoptotic rates of the T24 cells under Gln deprivation.

Effect of Gln on STAT3 expression in T24 cells. To verify the association between Gln and STAT3, the groups of cells were treatd with 0,150 or $300 \mathrm{mg} / \mathrm{l} \mathrm{Gln}$ and we then examined STAT3 expression at the protein level (Fig. 6A and B). The results of western blot analysis revealed that the expression of
c-Myc, Bcl2, PCNA and STAT3 (including total-STAT3, and p-Y705-STAT3/total-STAT3) decreased gradually with the decreasing Gln concentrations at $48 \mathrm{~h}$. This findings clearly suggests that Gln promotes the proliferation and decreases the apoptosis of T24 bladder cancer cells by promoting STAT3 expression.

Glutaminolysis and ROS levels modulate STAT3 activation. We then sought to determine whether glutaminolysis and ROS levels regulate STAT3 expression. The expression levels of c-Myc, Bcl2, PCNA and STAT3 (including total-STAT3 and p-Y705-STAT3) in the $\mathrm{Gln}(+), \mathrm{Gln}(-), \mathrm{Gln}(-)+\alpha \mathrm{KG}, \mathrm{Gln}(-)+\mathrm{Glu}$, and $\mathrm{Gln}(-)+\mathrm{NAC}$ groups (Fig. $6 \mathrm{C}$ and $6 \mathrm{E}$ ) were analyzed. The results of western blot analysis revealed that proteins associated with proliferation (c-Myc, Bcl2 and PCNA) were expressed at higher levels in the $\mathrm{Gln}(-)+\alpha \mathrm{KG}, \mathrm{Gln}(-)+\mathrm{Glu}$, and Gln(-)+NAC groups than in the Gln(-) group. The expression of total-STAT3 and p-Y705-STAT3/total-STAT3 was efficiently restored in the $\mathrm{Gln}(-)+\alpha \mathrm{KG}$ and $\mathrm{Gln}(-)+\mathrm{Glu}$ groups compared with the Gln(-) group (Fig. 6D). In addition, the expression of 
A

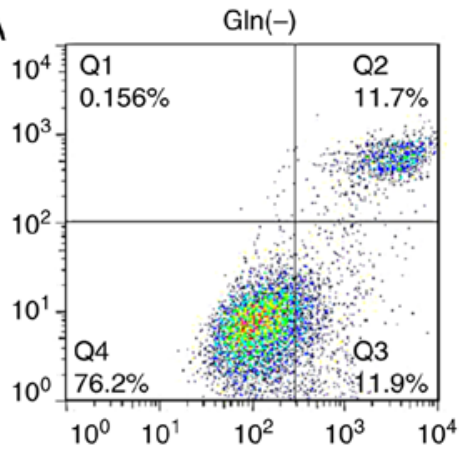

$\mathrm{G} \ln (-)+\alpha K G$

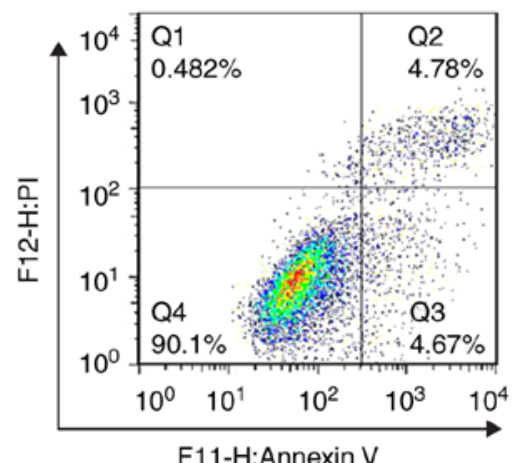

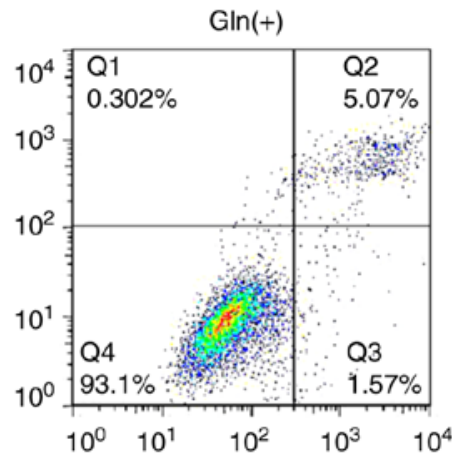

Gln(-)+Glu

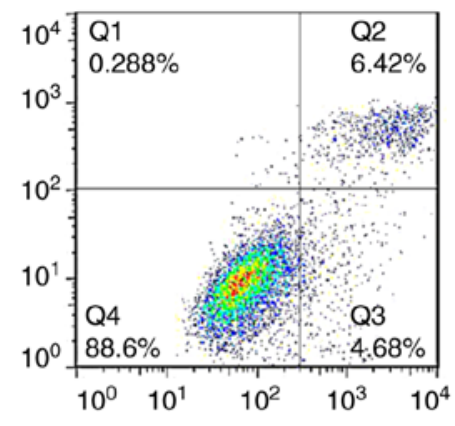

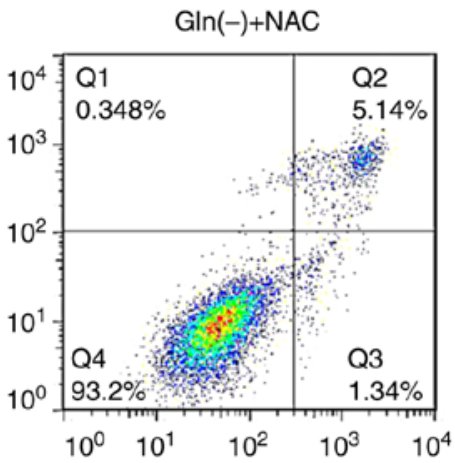

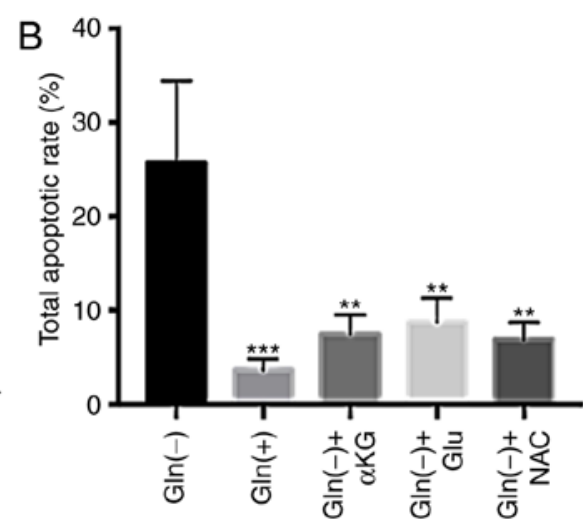

Figure 5. Gln metabolism affects T24 cell apoptosis. (A) The apoptotic effects of different conditions, including Gln(-), Gln(+), Gln(-)+ $\alpha$ KG, Gln(-)+Glu, and Gln(-)+NAC, were assessed with flow cytometry at 48 h. (B) Semi-quantitative analysis of the apoptotic rates in independent experiments repeated 3 times; $\mathrm{Gln}(-)$ was used as the control condition. One-way ANOVA with a test for homogeneity of variance was used to compare the cell lines. ${ }^{* *} \mathrm{P}<0.01,{ }^{* * * *} \mathrm{P}<0.001$. Gln, glutamine; Glu, L-glutamic acid dimethyl ester hydrochloride.

total-STAT3 and p-Y705-STAT3/total-STAT3 was higher in the $\mathrm{Gln}(-)+\mathrm{NAC}$ group than in the Gln(-) group (Fig. 6F).

\section{Discussion}

Bladder cancer ranks 13th in terms of mortality, although mortality rates are increasing in most countries $(1,21)$. The majority of cases are transitional cell carcinoma (TCC), a neoplasm originating from transitional urothelial cells. The T24 cell line was derived from malignant bladder cancer undergoing progression to the muscle layer of the bladder wall, in contrast to cell lines derived from non-muscle-invasive bladder cancer, an early-stage type of bladder cancer (22). Gln metabolism contributes to T24 cancer cell proliferation. Indeed, Lea et al (23) found that Gln deprivation affected the proliferation rates of several bladder cancer cell lines, including the T24 and UM-UC-3 lines.

In this study, the T24 cell proliferation rates were positively associated with the Gln concentrations. Compared with that in the $G \ln (+)$ group, the proportion of cells in the $S$ phase was much higher in the $G \ln (-)$ group. In response to Gln deprivation, $\mathrm{K}$-Ras-driven cancer cells can arrest in either the $\mathrm{S}$ or $\mathrm{G} 2 / \mathrm{M}$ phase due to insufficient nucleotide biosynthesis (24-26). Aspartate, which is essential for nucleotide biosynthesis, is produced in a transamination reaction catalyzed by GOT2. Therefore, in the absence of Gln, a lack of aspartate for the GOT2 catalytic reaction leads to replication stress due to insufficient nucleotides, which may be the cause of the $\mathrm{S}$ phase arrest observed in this study. Consistent with this hypothesis,
$\mathrm{S}$ phase arrest can be overcome by providing cells with $\alpha$-ketoglutarate and aspartic acid (24). To confirm the direct association between Gln and bladder cancer, T24 cell proliferation was further examined by using the Gln analog, Don. Compared to Gln alone [in the Gln(+) group], Don markedly inhibited the proliferation of the T2 4 cells and significantly decreased the protein expression of the key enzymes, GLS and GLUD1, which participate in Gln metabolism.

Cancer cells undergo metabolic transformation to meet their increased anabolic demand for glycolytic and TCA cycle intermediates to synthesize important biomolecules required for cell growth. The key to this metabolic transformation is the mitochondrial excretion of citric acid, which is used in the TCA cycle to produce the cytosolic acetyl-CoA necessary for lipid biosynthesis. Upon the loss of mitochondrial citrate, cancer cells become dependent on the 'conditionally essential' amino acid Gln, which serves as a supplemental carbon source for the TCA cycle.

We further explored the mechanism through which Gln affects T24 proliferation from the perspectives of ATP production, ROS neutralization and direct stimulation of the production of STAT3 as a signaling factor. The supplementation of Gln-deprived T24 cells with Gln catabolism intermediates (Glu and $\alpha \mathrm{KG}$ ) restored both the ATP levels and proliferation rates to a certain extent, which illustrated that Gln also affects the proliferation of T24 bladder cancer cells through the catabolic pathway. Gln-derived carbon enters the TCA cycle following the conversion of Glu to $\alpha \mathrm{KG}$. Gln-derived carbon also contributes to ATP production through its oxidation in 


\section{A}
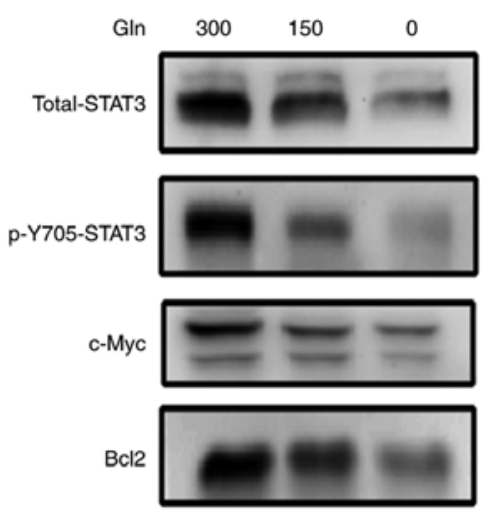

$\beta$-actin

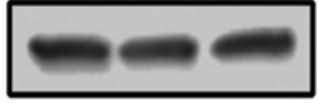

C
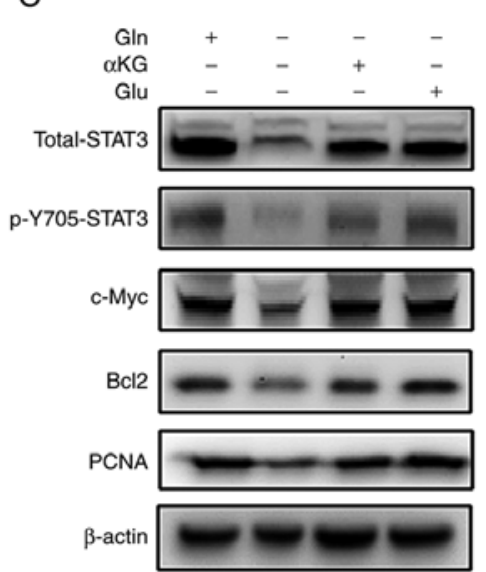
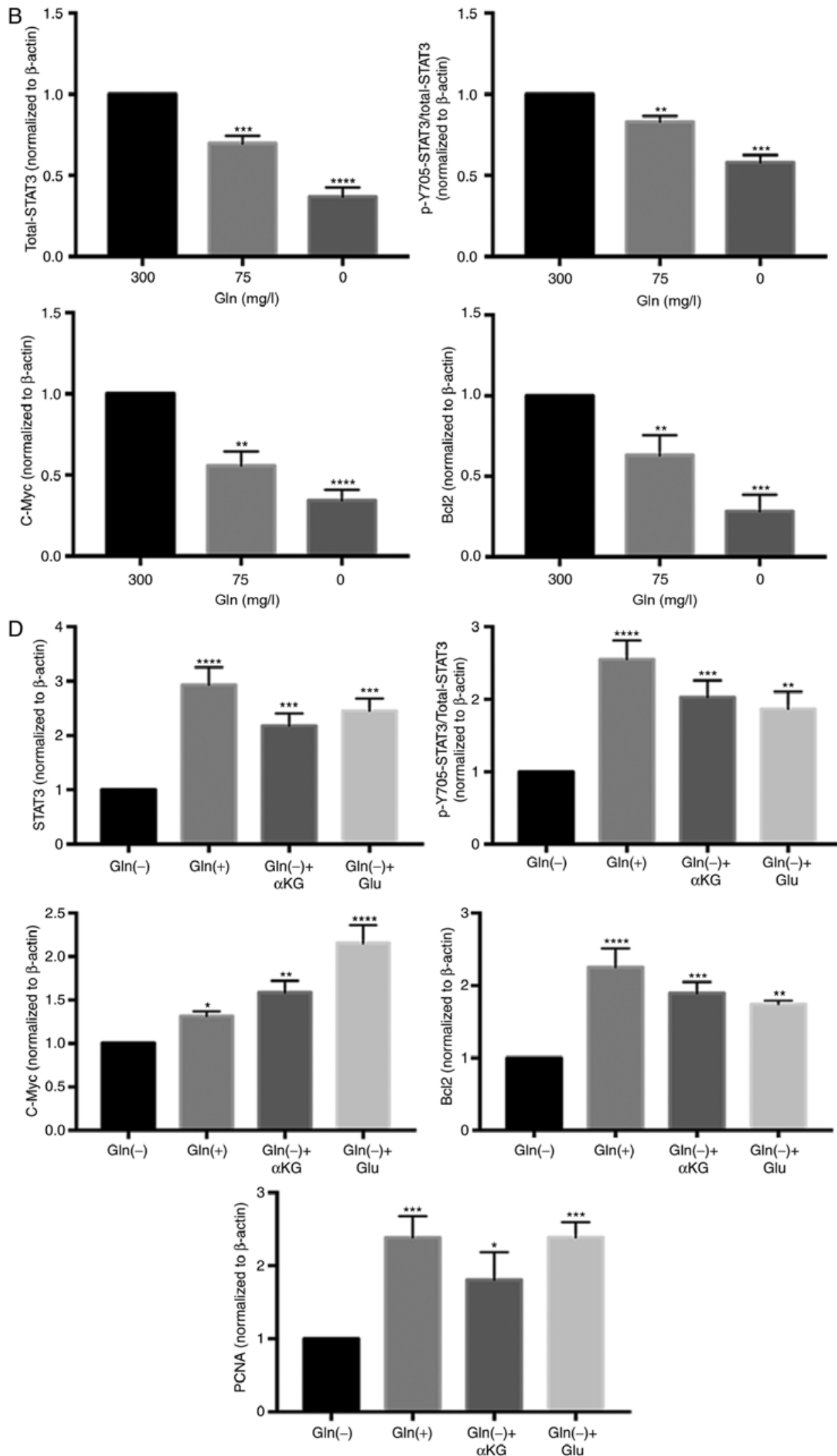

Figure 6. Gln affects STAT3 by affecting ROS and glutaminolysis. (A) Western blot analysis of proteins related to proliferation (STAT3 and c-Myc) and apoptosis $(\mathrm{Bcl} 2)$ at $48 \mathrm{~h}$. (B) Quantitative analysis of the results in (A) from independent experiments repeated 3 times. (C) Western blot analysis of the effects of the glutaminolysis intermediates $\alpha \mathrm{KG}$ and Glu on the expression of proteins in the STAT3 pathway. (D) Quantitative analysis of the results in (C) from independent experiments repeated 3 times.

the TCA cycle (27). Accordingly, cell-permeable forms of Glu and $\alpha \mathrm{KG}$, which have previously been reported to effectively supply Glu and $\alpha$ KG intracellularly, can be substituted for Gln to support cancer cell metabolism and ATP production $(10,27)$. 

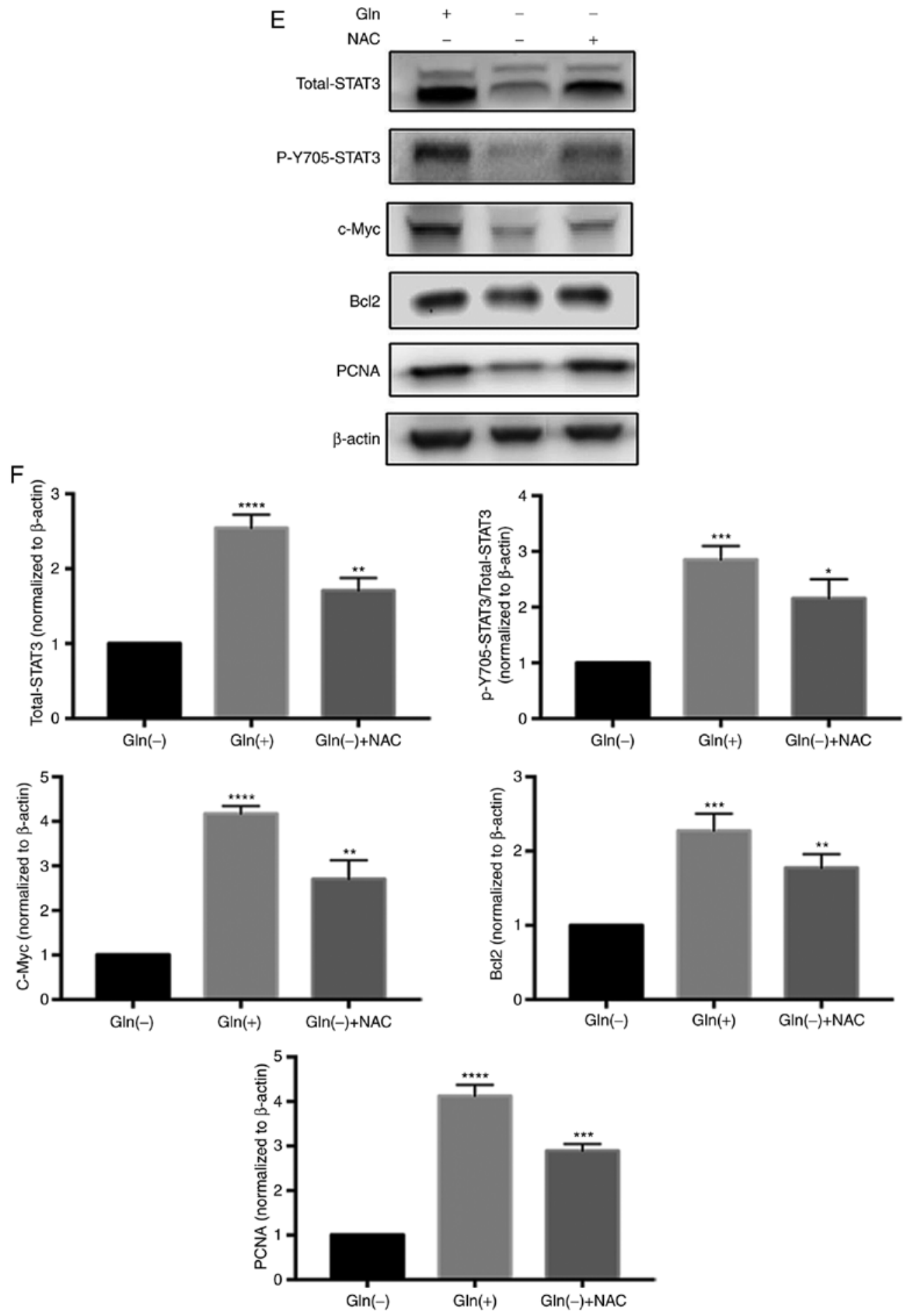

Figure 6. Continued. (E) Western blot analysis of the effects of altering ROS concentrations in the TME with the ROS scavenger NAC on the expression of proteins in the STAT3 pathway. (F) Quantitative analysis of the results in (E) from independent experiments repeated 3 times. Gln(-) was used as the control condition. One-way ANOVA with a test for homogeneity of variance was used to compare the groups. ${ }^{*} \mathrm{P}<0.05,{ }^{* *} \mathrm{P}<0.01,{ }^{* * *} \mathrm{P}<0.001,{ }^{* * * *} \mathrm{P}<0.0001$. Gln, glutamine; Glu, L-glutamic acid dimethyl ester hydrochloride; STAT3, signal transducer and activator of transcription 3; ROS, reactive oxygen species.

In addition, Gln is a regulator of intracellular redox balance associated with glutathione synthesis and metabolic NADPH production. These functions of Gln require its metabolic processing and account for its effects on the viability of T24 cells. The results of this study revealed that Gln starvation induced cell death by augmenting the ROS levels in T24 bladder cancer cells. We investigated the possibility that Gln promotes the survival of T24 cells by mitigating the toxic effects of increased ROS production. Notably, the addition of a ROS scavenger to the culture medium evidently increased the proliferation of the Gln-deprived T24 cells, suggesting that Gln is required for the alleviation of the effects of enhanced ROS production. Therefore, Gln controls the proliferation of T24 cells, which are Gln-dependent bladder cancer cells, in a manner dependent on its metabolic use. These findings are inconsistent with the hypothesis described in the study 
by Cacace et al (13), namely that Gln controls cancer cell proliferation independently of ROS production modulation.

Subsequently, we wished to determine whether Gln affects T24 proliferation by modulating STAT3 activation. Yang et al (28) proposed that Gln regulates the activation of STAT3, a signaling pathway mediator that regulates cancer hallmarks in invasive OVCA cells. The inhibition of Gln utilization in these cancer cells through GLS inactivation significantly reduced phosphorylated STAT3 expression (29). However, whether this phenomenon is applicable to bladder cancer has remained unknown. Activated STAT3 has been detected in bladder cancer (30), and the inhibition of STAT3 activity with antisense oligonucleotides, decoy oligonucleotides and siRNA has been shown to result in the apoptosis and reduced growth of tumor cells (31). Notably, STAT3 expression is closely related to T24 bladder cancer cell proliferation. As mentioned previously, STAT3 pathway activation and inactivation clearly affect T24 cell proliferation. For example, it has been identified that the inhibition of STAT3 efficiently decreases T24 cell proliferation $(32,33)$. The rapid activation of STAT3 has also been found to modulate the proliferation of the T24 cells (34). In this study, we did not aim to repeat such experiments. Instead, we explored the association between Gln and the STAT3 pathway. We found that STAT3 was an essential mediator of Gln-dependent T24 cancer cell proliferation and that Gln promoted total-STAT3 and p-Y705-STAT3/total-STAT3 expression. To ascertain whether Gln affects STAT3 expression to modulate cancer cell proliferation and apoptosis, we also detected c-Myc and $\mathrm{Bcl} 2$, which have previously been reported to be influenced by Gln and STAT3. The oncogene c-Myc coordinates the expression of genes necessary for cells to engage in Gln catabolism that exceeds the cellular requirements for protein and nucleotide biosynthesis (35). STAT3 mostly mediates the rapid activation of the c-Myc gene (36). Information on the metabolic regulation of $\mathrm{Bcl} 2$ proteins may provide insight into alternative routes of apoptosis activation. For example, cells surviving Gln withdrawal exhibit a particularly enhanced expression of BIM and the binding of BIM to Bcl2 (37). Huang et al (38) found that Roxyl-zhc-84 reduced JAK1 and STAT3 phosphorylation and markedly downregulated the expression of the anti-apoptotic protein, Bcl2, which is known as a STAT3 target gene.

STAT3 is constitutively phosphorylated on tyrosine in various tumor types (39), and this phosphorylation is associated with a reduced ROS production, delayed senescence and protection from apoptosis. Both nuclear p-Y705-STAT3 and mitochondrial p-S727-STAT3 can promote cell survival and reduce ROS production (40). Previous studies have demonstrated that the inactivation of STAT3 promotes apoptosis by decreasing $\mathrm{Bcl} 2$ expression $(41,42)$ and that it is feasible to induce cancer cell apoptosis by regulating ROS-modulated STAT3 expression (43,44). In addition, Cetinbas et al (45) hypothesized that increases in ROS production compensate for the increases in Gln ingestion and utilization. As described above, Gln can promote T24 cell proliferation through glutaminolysis, regulating ROS production and promoting STAT3 expression. It was previously unclear whether Gln affects bladder cancer cell T24 proliferation by activating STAT3 through ROS and glutaminolysis. The results of this study revealed that Gln can act intracellularly to activate STAT3 through glutaminolysis and mediate the proliferative effects of
STAT3, indicating that Gln affects STAT3 expression via its catabolism. Under Gln deprivation, the replenishment of Gln catabolism intermediates ( $\alpha \mathrm{KG}$ and Glu) significantly restored the STAT3 expression levels. Similarly, the elimination of intracellular ROS with NAC initially reduced the use of Gln for ROS scavenging, causing Gln to accumulate in cells; this effect was directly reflected by the total STAT3 expression. These findings identify the critical role of ROS in regulating STAT3 expression. These experiments reveal that STAT3 is modulated by glutaminolysis and ROS levels. In other words, Gln can induce T24 bladder cancer cell proliferation mainly through STAT3 by affecting ATP and ROS generation.

Above all, this study highlights the essential role of Gln in the proliferation of Gln-dependent T24 bladder cancer cells. In addition, our findings regarding the cause-effect relationship between Gln metabolism and proliferation in the T24 bladder cancer cell line show the importance of Gln-dependent cancer therapy in clinical practice. The observation that KRas-driven Gln-dependent cancer cells arrest in the $S$ phase due to a lack of aspartic acid (46) provides a compelling treatment opportunity for KRas-driven late metastatic bladder cancer. In fact, Ras oncogene mutations cooperate with $\beta$-catenin activation to drive bladder tumourigenesis (47). It has also been reported that the inhibition of STAT3 partially reverses gemcitabine-induced migration, chemoresistance, and tumor relapse (48).

Radical cystectomy, regarded for decades as the standard treatment for muscle-invasive bladder cancer, is associated with significant morbidity and high complication rates after surgery. Interest in alternative treatment options that protect the bladder has increased (49-51). Three methods have been widely recognized as bladder-protecting therapies: Transurethral resection of bladder tumors (TURBT), chemotherapy and radiation therapy (51-53). However, radiation therapy is often associated with recurrence and distant metastasis, as several tumors are radioresistant; thus, its implementation can result in complications $(54,55)$. Furthermore, the search for strategies with which to prevent the recurrence of bladder cancer after using chemotherapeutics, such as gemcitabine, a frequently used drug in the treatment of bladder cancer, is a vital part of clinical chemotherapy. The identification of prognostic and predictive biomarkers may provide other strategies through which patients can avoid radical cystectomy $(56,57)$.

Understanding the role of Gln in STAT3 activation may aid in the prevention and treatment of Gln-dependent bladder cancer in clinical practice from the perspective of metabolism. Thus far, several GLS inhibitors have been developed in the search for selective inhibitors of Gln catabolism; these agents, including 968, BPTES and CB-389, have exhibited tumor-suppressive activities in preclinical models (58-61). In addition, radiolabeled Gln can be used to locate tumors, and currently popular carrier materials can be used with Gln analogs to block Gln metabolism in tumor cells at the gene level for tumor starvation.

In conclusion, the findings of this study indicated that Gln affects the proliferation of T24 bladder cancer cells mainly by modifying STAT3 expression. This effect is dependent on the metabolic use of Gln and on the participation of Gln in the regulation of ROS levels. Gln deprivation results in $\mathrm{K}$-Ras-driven bladder cancer cell arrest in $\mathrm{S}$ phase. Notably, $\mathrm{S}$ phase-arrested cells are vulnerable to the cytotoxic drugs 
capecitabine, paclitaxel and rapamycin $(24,26)$. Thus, Gln deprivation mediates the 'synthetic lethality' of KRas-driven cancer cells upon capecitabine, paclitaxel and rapamycin treatment. The findings of this study further establish the potential for exploiting metabolic changes in cancer cells that confer novel opportunities for therapeutic intervention.

\section{Acknowledgements}

The authors would like to thank the members of the Key Laboratory of Urinary System Diseases (Affiliated Hospital of Qingdao University). The authors are also grateful to the Department of Urology, Affiliated Hospital of Qingdao University for providing helpful discussions with regards to this manuscript.

\section{Funding}

This study was financially supported by the National Natural Science Foundation of China (grant nos. 81772713, 81472411, 81372752 and 81401899); the Taishan Scholar Program of Shandong Province (tsqn20161077); the Natural Science Foundation (ZR2014HM088) and the Key Research and Development Program (2018GSF118197) of Shandong Province; the China Postdoctoral Science Foundation (2017M622144) and Qingdao Postdoctoral Application Research Project; and the Qingdao Young Scientist Applied Basic Research Fund (15-9-1-105-jch. 15-9-1-51-jch).

\section{Availability of data and materials}

All data generated or analyzed during this study are included in this published article or are available from the corresponding author on reasonable request.

\section{Authors' contributions}

NS, YL, YC LS, YW and HN conceived and designed the study. NS, LW, DL and ZL performed the experiments and analyzed the data. NS and LS wrote the manuscript. YW and $\mathrm{HN}$ reviewed and edited the manuscript. All authors have read and approved the final manuscript.

\section{Ethics approval and consent to participate}

Not applicable.

\section{Patient consent for publication}

Not applicable.

\section{Competing interests}

The authors declare that they have no competing interests.

\section{References}

1. Antoni S, Ferlay J, Soerjomataram I, Znaor A, Jemal A and Bray F: Bladder cancer incidence and mortality: A global overview and recent trends. Eur Urol 71: 96-108, 2017.
2. Zhang J, Pavlova NN and Thompson C: Cancer cell metabolism: The essential role of the nonessential amino acid, glutamine. EMBO J 36: 1302-1315, 2017.

3. Daye D and Wellen KE: Metabolic reprogramming in cancer: Unraveling the role of glutamine in tumorigenesis. Semin Cell Dev Biol 23: 362-369, 2012.

4. DeBerardinis RJ, Mancuso A, Daikhin E, Nissim I, Yudkoff M, Wehrli $\mathrm{S}$ and Thompson CB: Beyond aerobic glycolysis: Transformed cells can engage in glutamine metabolism that exceeds the requirement for protein and nucleotide synthesis. Proc Natl Acad Sci USA 104: 19345-19350, 2007.

5. Son J, Lyssiotis CA, Ying H, Wang X, Hua S, Ligorio M, Perera RM, Ferrone CR, Mullarky E, Shyh-Chang N, et al: Glutamine supports pancreatic cancer growth through a KRAS-regulated metabolic pathway. Nature 496: 101-105, 2013.

6. Weinberg F, Hamanaka R, Wheaton WW, Weinberg S, Joseph J, Lopez M, Kalyanaraman B, Mutlu GM, Budinger GR and Chandel NS: Mitochondrial metabolism and ROS generation are essential for Kras-mediated tumorigenicity. Proc Natl Acad Sci USA 107: 8788-8793, 2010.

7. Rajagopalan KN and DeBerardinis RJ: Role of glutamine in cancer: Therapeutic and imaging implications. J Nucl Med 52: 1005-1008, 2011.

8. Matés JM, Pérez-Gómez C, Núñez de Castro I, Asenjo M and Márquez J: Glutamine and its relationship with intracellular redox status, oxidative stress and cell proliferation/death. Int J Biochem Cell Biol 34: 439-458, 2002.

9. Ratnikov B, Aza-Blanc P, Ronai ZA, Smith JW, Osterman AL and Scott DA: Glutamate and asparagine cataplerosis underlie glutamine addiction in melanoma. Oncotarget 6: 7379-7389, 2015.

10. Shanware NP, Bray K, Eng CH, Wang F, Follettie M, Myers J, Fantin VR and Abraham RT: Glutamine deprivation stimulates mTOR-JNK-dependent chemokine secretion. Nat Commun 5: 4900, 2014.

11. Wise DR and Thompson CB: Glutamine addiction: A new therapeutic target in cancer. Trends Biochem Sci 35: 427-433, 2010.

12. Le A,Lane AN,HamakerM,BoseS, Gouw A,Barbi J,TsukamotoT, Rojas CJ, Slusher BS, Zhang H, et al: Glucose-independent glutamine metabolism via TCA cycling for proliferation and survival in B cells. Cell Metab 15: 110-121, 2012.

13. Cacace A, Sboarina M, Vazeille T and Sonveaux P: Glutamine activates STAT3 to control cancer cell proliferation independently of glutamine metabolism. Oncogene 36: 2074-2084, 2017.

14. Fukada T, Hibi M, Yamanaka Y, Takahashi-Tezuka M, Fujitani Y, Yamaguchi T, Nakajima K and Hirano T: Two signals are necessary for cell proliferation induced by a cytokine receptor gp130: Involvement of STAT3 in anti-apoptosis. Immunity 5: 449-460, 1996.

15. Zhang Y, Du XL, Wang CJ, Lin DC, Ruan X, Feng YB, Huo YQ, Peng H, Cui JL, Zhang TT, et al: Reciprocal activation between PLK1 and Stat 3 contributes to survival and proliferation of esophageal cancer cells. Gastroenterology 142: 521-530, 2012.

16. Mandal PK, Ren Z, Chen X, Xiong C and McMurray JS: Structure-affinity relationships of glutamine mimics incorporated into phosphopeptides targeted to the $\mathrm{SH} 2$ domain of signal transducer and activator of transcription 3. J Med Chem 52: 6126-6141, 2009

17. FabrícioF, deOliveiraCP,Rockenbach L,MendesFB,Bergamin L, Jandrey EH, Edelweiss MI, Guterres SS, Pohlmann AR and Battastini AM: Pharmacological improvement and preclinical evaluation of methotrexate-loaded lipid-core nanocapsules in a glioblastoma model. J Biomed Nanotechnol 11: 1808-1818, 2015.

18. Castaneda JM, Hua R, Miyata H, Oji A, Guo Y, Cheng Y, Zhou T, Guo X, Cui Y, Shen B, et al: TCTE1 is a conserved component of the dynein regulatory complex and is required for motility and metabolism in mouse spermatozoa. Proc Natl Acad Sci USA 114: E5370-E5378, 2017.

19. Chen W, Shen X, Hu Y, Xu K, Ran Q, Yu Y, Dai L, Yuan Z, Huang L, Shen T and Cai K: Surface functionalization of titanium implants with chitosan-catechol conjugate for suppression of ROS-induced cells damage and improvement of osteogenesis. Biomaterials 114: 82-96, 2017.

20. Dietrich F, Figueiró F, Filippi-Chiela EC, Cappellari AR, Rockenbach L, Tremblay L, de Paula PB, Roesler R, Filho AB, Sévigny J, et al: Ecto-5'-nucleotidase/CD73 contributes to the radiosensitivity of T24 human bladder cancer cell line. J Cancer Res Clin Oncol 144: 469-482, 2018.

21. Ferlay J, Soerjomataram I, Dikshit R, Eser S, Mathers C, Rebelo M, Parkin DM, Forman D and Bray F: Cancer incidence and mortality worldwide: Sources, methods and major patterns in GLOBOCAN 2012. Int J Cancer 136: E359-E386, 2015. 
22. Rockenbach L, Bavaresco L, Fernandes Farias P, Cappellari AR, Barrios CH, Bueno Morrone F and Oliveira Battastini AM: Alterations in the extracellular catabolism of nucleotides are involved in the antiproliferative effect of quercetin in human bladder cancer T24 cells. Urol Oncol 31: 1204-1211, 2013.

23. Lea MA, Altayyar M and desBordes C: Inhibition of growth of bladder cancer cells by 3-(3-Pyridinyl)-1-(4-pyridinyl)-2-propen1-one in combination with other compounds affecting glucose metabolism. Anticancer Res 35: 5889-5899, 2015.

24. Saqcena M, Mukhopadhyay S, Hosny C, Alhamed A, Chatterjee A and Foster DA: Blocking anaplerotic entry of glutamine into the TCA cycle sensitizes K-Ras mutant cancer cells to cytotoxic drugs. Oncogene 34: 2672-2680, 2015.

25. Gaglio D, Soldati C, Vanoni M, Alberghina L and Chiaradonna F: Glutamine deprivation induces abortive s-phase rescued by deoxyribonucleotides in k-ras transformed fibroblasts. PLoS One 4: e4715, 2009.

26. Saqcena M, Patel D, Menon D, Mukhopadhyay S and Foster DA: Apoptotic effects of high-dose rapamycin occur in S-phase of the cell cycle. Cell Cycle 14: 2285-2292, 2015.

27. Fan J, Kamphorst JJ, Mathew R, Chung MK, White E, Shlomi T and Rabinowitz JD: Glutamine-driven oxidative phosphorylation is a major ATP source in transformed mammalian cells in both normoxia and hypoxia. Mol Syst Biol 9: 712, 2013.

28. Yang L, Moss T, Mangala LS, Marini J, Zhao H, Wahlig S, Armaiz-Pena G, Jiang D, Achreja A, Win J, et al: Metabolic shifts toward glutamine regulate tumor growth, invasion and bioenergetics in ovarian cancer. Mol Syst Biol 10: 728, 2014.

29. Guo L, Zhou B, Liu Z, Xu Y, Lu H, Xia M, Guo E, Shan W, Chen G and Wang C: Blockage of glutaminolysis enhances the sensitivity of ovarian cancer cells to PI3K/mTOR inhibition involvement of STAT3 signaling. Tumour Biol 37: 11007-11015, 2016.

30. Santoni M, Conti A, Piva F, Massari F, Ciccarese C, Burattini L, Cheng L, Lopez-Beltran A, Scarpelli M, Santini D, et al: Role of STAT3 pathway in genitourinary tumors. Future Sci 1: FSO15, 2015.

31. Zhang B, Lu Z, Hou Y, Hu J and Wang C: The effects of STAT3 and survivin silencing on the growth of human bladder carcinoma cells. Tumour Biol 35: 5401-5407, 2014.

32. Wu F, Chen Y, Li Y, Ju J, Wang Z and Yan D: RNA-interference-mediated $\mathrm{Cdc} 42$ silencing down-regulates phosphorylation of STAT3 and suppresses growth in human bladder-cancer cells. Biotechnol Appl Biochem 49: 121-128, 2008.

33. Tsujita Y, Horiguchi A, Tasaki S, Isono M, Asano T, Ito K, Asano T, Mayumi Y and Kushibiki T: STAT3 inhibition by WP1066 suppresses the growth and invasiveness of bladder cancer cells. Oncol Rep 38: 2197-2204, 2017.

34. Chen RJ, Ho YS, Guo HR and Wang YJ: Rapid activation of Stat 3 and ERK $1 / 2$ by nicotine modulates cell proliferation in human bladder cancer cells. Toxicol Sci 104: 283-293, 2008.

35. Wise DR, DeBerardinis RJ, Mancuso A, Sayed N, Zhang XY, Pfeiffer HK, Nissim I, Daikhin E, Yudkoff M, McMahon SB and Thompson CB: Myc regulates a transcriptional program that stimulates mitochondrial glutaminolysis and leads to glutamine addiction. Proc Natl Acad Sci USA 105: 18782-18787, 2008.

36. Kiuchi N, Nakajima K, Ichiba M, Fukada T, Narimatsu M, Mizuno K, Hibi M and Hirano T: STAT3 is required for the gp130-mediated full activation of the c-myc gene. J Exp Med 189: 63-73, 1999.

37. Bajpai R, Matulis SM, Wei C, Nooka AK, Von Hollen HE, Lonial S, Boise LH and Shanmugam M: Targeting glutamine metabolism in multiple myeloma enhances BIM binding to BCL-2 eliciting synthetic lethality to venetoclax. Oncogene 35: 3955-3964, 2015.

38. Huang Z, Zhou W, Li Y, Cao M, Wang T, Ma Y, Guo Q, Wang X, Zhang C, Zhang C, et al: Novel hybrid molecule overcomes the limited response of solid tumours to HDAC inhibitors via suppressing JAK1-STAT3-BCL2 signalling. Theranostics 8 : 4995-5011, 2018.

39. Demaria M, Giorgi C, Lebiedzinska M, Esposito G, D'Angeli L, Bartoli A, Gough DJ, Turkson J, Levy DE, Watson CJ, et al: A STAT3-mediated metabolic switch is involved in tumour transformation and STAT3 addiction. Aging (Albany NY) 2: 823-842, 2010.

40. Poli V and Camporeale A: STAT3-mediated metabolic reprograming in cellular transformation and implications for drug resistance. Front Oncol 5: 121, 2015.

41. Tan Y, Huang N, Zhang X, Hu J, Cheng S, Pi L and Cheng Y: KIAA0247 suppresses the proliferation, angiogenesis and promote apoptosis of human glioma through inactivation of the AKT and Stat3 signaling pathway. Oncotarget 7: 87100-87113, 2016.
42. Wang X, Qiu W, Zhang G, Xu S, Gao Q and Yang Z: MicroRNA-204 targets JAK2 in breast cancer and induces cell apoptosis through the STAT3/BCl-2/survivin pathway. Int J Clin Exp Pathol 8: 5017-5025, 2015.

43. Sun Q, Lu NN and Feng L: Apigetrin inhibits gastric cancer progression through inducing apoptosis and regulating ROS-modulated STAT3/JAK2 pathway. Biochem Biophys Res Commun 498: 164-170, 2018.

44. Cai N, Zhou W, Ye LL, Chen J, Liang QN, Chang G and Chen JJ: The STAT3 inhibitor pimozide impedes cell proliferation and induces ROS generation in human osteosarcoma by suppressing catalase expression. Am J Transl Res 9: 3853-3866, 2017.

45. Cetinbas N, Daugaard M, Mullen AR, Hajee S, Rotblat B, Lopez A, Li A, DeBerardinis RJ and Sorensen PH: Loss of the tumor suppressor Hacel leads to ROS-dependent glutamine addiction. Oncogene 34: 4005-4010, 2015.

46. Mukhopadhyay S, Saqcena M and Foster DA: Synthetic lethality in KRas-driven cancer cells created by glutamine deprivation. Oncoscience 2: 807-808, 2015.

47. Ahmad I, Patel R, Liu Y, Singh LB, Taketo MM, Wu XR, Leung HY and Sansom OJ: Ras mutation cooperates with $\beta$-catenin activation to drive bladder tumourigenesis. Cell Death Dis 2: e124, 2011.

48. Zhang Z, Duan Q, Zhao H, Liu T, Wu H, Shen Q, Wang C and Yin T: Gemcitabine treatment promotes pancreatic cancer stemness through the Nox/ROS/NF- $\mathrm{KB} / \mathrm{STAT} 3$ signaling cascade. Cancer Lett 382: 53-63, 2016.

49. Jacobs BL, Lee CT and Montie JE: Bladder cancer in 2010: How far have we come? CA Cancer J Clin 60: 244-272, 2010.

50. Kotwal S, Choudhury A, Johnston C, Paul AB, Whelan P and Kiltie AE: Similar treatment outcomes for radical cystectomy and radical radiotherapy in invasive bladder cancer treated at a United Kingdom specialist treatment center. Int J Radiat Oncol Biol Phys 70: 456-463, 2008.

51. Russell CM, Lebastchi AH, Borza T, Spratt DE and Morgan TM: The role of transurethral resection in trimodal therapy for muscle-invasive bladder cancer. Bladder Cancer 2: 381-394, 2016.

52. Kulkarni GS, Hermanns T, Wei Y, Bhindi B, Satkunasivam R, Athanasopoulos P, Bostrom PJ, Kuk C, Li K, Templeton AJ, et al: Propensity score analysis of radical cystectomy versus bladder-sparing tri-modal therapy in the setting of a multidisciplinary bladder cancer clinic. J Clin Oncol 35: 2299-2305, 2017.

53. Rödel C, Grabenbauer GG, Kühn R, Papadopoulos T, Dunst J, Meyer M, Schrott KM and Sauer R: Combined-modality treatment and selective organ preservation in invasive bladder cancer: Long-term results. J Clin Oncol 20: 3061-3071, 2002.

54. James ND, Hussain SA, Hall E, Jenkins P, Tremlett J, Rawlings C Crundwell M, Sizer B, Sreenivasan T, Hendron C, et al: Radiotherapy with or without chemotherapy in muscle-invasive bladder cancer. N Engl J Med 366: 1477-1488, 2012.

55. Park JC, Citrin DE, Agarwal PK and Apolo AB: Multi-modal management of muscle-invasive bladder cancer. Curr Probl Cancer 38: 80-108, 2014.

56. Chen RC, Shipley WU, Efstathiou JA and Zietman AL: Trimodality bladder preservation therapy for muscle-invasive bladder cancer. J Natl Compr Cancer Netw 11: 952-960, 2013.

57. Shrivastava S, Mansure JJ, Almajed W, Cury F, Ferbeyre G, Popovic M, Seuntjens J and Kassouf W: The role of HMGB1 in radioresistance of bladder cancer. Mol Cancer Ther 15: 471-479, 2016.

58. Wang JB, Erickson JW, Fuji R, Ramachandran S, Gao P, Dinavahi R, Wilson KF, Ambrosio AL, Dias SM, Dang CV and Cerione RA: Targeting mitochondrial glutaminase activity inhibits oncogenic transformation. Cancer Cell 18: 207-219, 2010.

59. Gross MI, Demo SD, Dennison JB, Chen L, Chernov-Rogan T, Goyal B, Janes JR, Laidig GJ, Lewis ER, Li J, et al: Antitumor activity of the glutaminase inhibitor CB-839 in triple-negative breast cancer. Mol Cancer Ther 13: 890-901, 2014.

60. Xiang Y, Stine ZE, Xia J, Lu Y, O'Connor RS, Altman BJ, Hsieh AL, Gouw AM, Thomas AG, Gao P, et al: Targeted inhibition of tumor-specific glutaminase diminishes cell-autonomous tumorigenesis. J Clin Invest 125: 2293-2306, 2015.

61. Stalnecker CA, Ulrich SM,Li Y, Ramachandran S, McBrayer MK, DeBerardinis RJ, Cerione RA and Erickson JW: Mechanism by which a recently discovered allosteric inhibitor blocks glutamine metabolism in transformed cells. Proc Natl Acad Sci USA 112: 394-399, 2015.

This work is licensed under a Creative Commons Attribution-NonCommercial-NoDerivatives 4.0 International (CC BY-NC-ND 4.0) License. 